\title{
Mesothelioma patient derived tumor xenografts with defined BAP1 mutations that mimic the molecular characteristics of human malignant mesothelioma
}

Neetu Kalra ${ }^{1}$, Jingli Zhang ${ }^{1}$, Anish Thomas ${ }^{1}$, Liqiang Xi ${ }^{2}$, Mitchell Cheung ${ }^{3}$, Jacqueline Talarchek ${ }^{3}$, Sandra Burkett ${ }^{4}$, Maria G Tsokos ${ }^{5}$, Yuanbin Chen ${ }^{1}$, Mark Raffeld ${ }^{2}$, Markku Miettinen², Ira Pastan ${ }^{6}$, Joseph R Testa ${ }^{3}$ and Raffit Hassan ${ }^{1 *}$

\begin{abstract}
Background: The development and evaluation of new therapeutic approaches for malignant mesothelioma has been sparse due, in part, to lack of suitable tumor models.

Methods: We established primary mesothelioma cultures from pleural and ascitic fluids of five patients with advanced mesothelioma. Electron microscopy and immunohistochemistry $(\mathrm{IHC})$ confirmed their mesothelial origin. Patient derived xenografts were generated by injecting the cells in nude or SCID mice, and malignant potential of the cells was analyzed by soft agar colony assay. Molecular profiles of the primary patient tumors, early passage cell cultures, and patient derived xenografts were assessed using mutational analysis, fluorescence in situ hybridization (FISH) analysis and IHC.
\end{abstract}

Results: Primary cultures from all five tumors exhibited morphologic and IHC features consistent to those of mesothelioma cells. Mutations of BAP1 and CDKN2A were each detected in four tumors. BAP1 mutation was associated with the lack of expression of BAP1 protein. Three cell cultures, all of which were derived from BAP1 mutant primary tumors, exhibited anchorage independent growth and also formed tumors in mice, suggesting that BAP1 loss may enhance tumor growth in vivo. Both early passage cell cultures and mouse xenograft tumors harbored BAP1 mutations and CDKN2A deletions identical to those found in the corresponding primary patient tumors.

Conclusions: The mesothelioma patient derived tumor xenografts with mutational alterations that mimic those observed in patient tumors which we established can be used for preclinical development of novel drug regimens and for studying the functional aspects of BAP1 biology in mesothelioma.

Keywords: Mesothelioma, Malignant effusions, BAP1, CDKN2A, Patient derived tumor xenografts

\section{Background}

Malignant mesothelioma is an asbestos-related aggressive tumor with poor prognosis, occurring in the mesothelial lining of pleural or peritoneal cavities. Malignant mesothelioma is a deadly and clinically challenging disease due to its low incidence, resistance to most chemotherapies, and complexity of tumor anatomy. Despite multimodality therapy, the median overall survival is less than a year for

\footnotetext{
*Correspondence: hassanr@mail.nih.gov

1Thoracic and Gl Oncology Branch, Center for Cancer Research, National Cancer Institute, National Institutes of Health, Bethesda, MD 20892, USA Full list of author information is available at the end of the article
}

patients with pleural tumors, and the 5-year survival rate is less than $15 \%$ for peritoneal mesothelioma [1].

The development and evaluation of new therapeutic approaches for malignant mesothelioma has been sparse due, in part, to lack of suitable tumor models. Efforts to generate clinically relevant tumor models have focused on two main approaches in the recent years: generation of primary tumor-derived cell lines and of mouse models. Primary tumor-derived cell lines have adapted to growth outside a natural tumor microenvironment and due to selective processes associated with long term culturing will develop genetic changes that are distinct

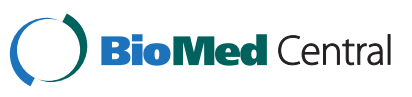

(c) 2015 Kalra et al.; licensee BioMed Central. This is an Open Access article distributed under the terms of the Creative Commons Attribution License (http://creativecommons.org/licenses/by/4.0), which permits unrestricted use, distribution, and reproduction in any medium, provided the original work is properly credited. The Creative Commons Public Domain Dedication waiver (http://creativecommons.org/publicdomain/zero/1.0/) applies to the data made available in this article unless otherwise stated. 
from the genetic stress imposed on tumors in patients [2-4]. Therefore even when propagated in vivo, they may not be suitable for preclinical testing of anti-cancer drugs or for studying the underlying gene expression associated with novel drug responses. Mouse models generated via engraftment of primary human tumors into immunecompromised mouse models have become increasingly popular for preclinical testing of anticancer drugs. However their usefulness depends upon the preservation of biological and morphological characteristics of the primary tumors [5]. Many of the currently available mesothelioma cell lines do not form tumors in mice, and others have been propagated in culture for many passages, leading to various cytogenetic changes. Thus, these lines often do not show much similarity with the original tumors [6].

The most common genetic alterations associated with mesothelioma, including CDKN2A deletions and NF2 mutations, have been known for about two decades [7-9]. More recently, mutations in the BAP1 tumor suppressor gene have been observed in 20-25\% of mesothelioma tumor samples $[10,11]$. BAP1, a nuclear ubiquitin hydrolase, plays an important role in various cellular processes including cell proliferation, DNA repair and regulation of gene expression at the chromatin level [12].

This study describes molecular and immunohistochemical characterization of five primary mesothelioma cell lines. By comparing mutational and immunohistochemical profiles between primary cell cultures, and patient derived xenografts, we report the stability of both the genetic profile and protein expression in the xenografts, highlighting their potential for exploring genetic changes associated with responses to established and novel drugs.

\section{Methods}

Pathological examination of the original tumor specimens All patients whose samples were utilized for this study were enrolled in Institutional Review Board approved protocols at the Center for Cancer Research, National Cancer Institute. All patients provided written informed consent which allowed the storage and use of body fluids, tumor samples and data that were collected for future research. Tumor samples obtained from five patients at the time of diagnosis or at the time of debulking surgery were evaluated by a pathologist to establish the diagnosis and characterize the subtype of mesothelioma.

\section{Establishment of early-passage mesothelioma cell cultures}

Early passage primary mesothelioma cell cultures were isolated from ascites or pleural fluid obtained from mesothelioma patients at the National Cancer Institute. The ascites or pleural fluid (100-1000 mL) was centrifuged at $1000 \mathrm{rpm}$ at room temperature for 3 minutes; the cell pellets were washed twice with phosphate buffered saline
(PBS), and red blood cells were removed using a BD Pharm Lyse $^{\mathrm{Tx}}$-Lysing Buffer kit (BD Bioscience, NJ), according to the manufacturer's instructions, and washed again two times with PBS. The cells were then resuspended in RPMI 1640 (Invitrogen, CA) supplemented with $2 \mathrm{mM}$ glutamine, 100 units penicillin-streptomycin, and $1 \mathrm{mM}$ sodium pyruvate (each from Invitrogen, CA) plus $20 \%$ fetal bovine serum (FBS) (Lonza, MD). The cells were seeded into $175 \mathrm{~mL}$ culture flasks at a density of $2.5-4.0 \times 10^{5}$ cells $/ \mathrm{ml}$. After incubating at $37^{\circ} \mathrm{C}$ in a humidified, $5 \% \mathrm{CO}_{2}$ atmosphere overnight, the medium containing non-adherent cells was replaced with fresh medium. The cultures were maintained by changing the medium depending upon the growth of the cells. To authenticate these cell lines for future use by us or other investigators we performed Short Tandem Repeats (STR) analysis of these cells.

\section{Immunohistochemistry}

Cells were detached using trypsin-EDTA and then washed and centrifuged. The cell pellets were fixed in formalin and embedded in paraffin. Tumor sections were prepared, and immunohistochemical studies were carried out for the mesothelial markers calretinin, WT1, CK5/6, and mesothelin and BAP1 using specific antibodies (Santa Cruz Biotechnology, TX). All immunostaining was carried out using an automated Ventana system (Ventana Medical Systems, AZ) using their UltraView polymer based detection system. IHC staining was scored semiquantitatively as follows: negative (less than $5 \%$ of cells stained), $1+$ positive (5- 50\%), and $2+$ positive (50-100\%).

\section{Electron microscopy}

Cells from all five cell lines were washed in PBS, fixed in PBS-buffered 2.5\% glutaraldehyde (Sigma Chemicals, $\mathrm{MO}$ ), postfixed in $0.5 \%$ osmium tetroxide and embedded into Spurr's epoxy resin (Ladd Research Industries, VT). Ultrathin sections were stained with uranyl acetate-lead citrate and viewed in a Phillips CM10 transmission electron microscope.

\section{Spectral karyotyping and fluorescent in situ hybridization} Spectral karyotyping was performed according to the manufacturer's protocol using 24-color human SKY paint probes (Applied Spectral Imaging, CA). Fluorescent in Situ Hybridization (FISH) analysis was carried out using a CDKN2A probe (Abbott Molecular, IL) encompassing the overlapping genes encoding $\mathrm{p} 16^{\mathrm{INK} 4 \mathrm{a}}$ and $\mathrm{p} 14^{\mathrm{ARF}}$. Spectral images of the hybridized metaphases were acquired using a SD301 SpectraCubeTM system (Applied Spectral Imaging Inc., CA) mounted on top of an epi-fluorescence microscope Axioplan 2 (Zeiss). Images were analyzed using Spectral Imaging 6.0 acquisition software (Applied Spectral Imaging Inc., CA). At least 10 SKY hybridized metaphases were analyzed in this experiment. FISH 
analyses were performed under an Axioplan 2 (Zeiss) fluorescence microscope coupled with a CCD camera (ASI) and images were captured with FISH view 5.5 software (Applied Spectral Imaging Inc., Vista, CA).

\section{Mutation analysis}

Genomic DNA was extracted from early passage cells using a DNA isolation kit (Mo-Bio Laboratories, CA). PCR was done using exon specific primers for the entire coding region of $B A P 1$, the tyrosine kinase domain of the EGFR, [13] and exons 2-9 of TP53. Polymerase Chain Reaction (PCR) products were purified and subjected to Sanger sequencing on an ABI PRISM sequencing apparatus (ABI Prism 310 Genetic Analyser, Applied Biosystems, NY). In addition, a panel of hotspot mutations in 7 genes (AKT1, BRAF, EBRR2, EGFR, $K R A S, N R A S$, and PIK3CA) was analyzed with pyrosequencing for single-nucleotide variants (SNVs) or with fragment analysis for insertions/deletions (indels). Briefly PCR amplification was initially performed with primers flanking the mutation hotspot under co-amplification at lower denaturation temperature (COLD)-PCR conditions and was followed by targeted pyrosequencing on a PyroMark Q24 instrument (Qiagen) or by capillary electrophoresis using a Genetic Analyzer 3130xl (Life Technologies) [14-20].

\section{Flow cytometry}

Mesothelin expression on early and late passage primary cell cultures were evaluated by flow cytometry using the anti-mesothelin primary antibody $(\mathrm{MN})$ as previously described [21].

\section{Western blotting}

Monolayers of confluent cells were washed twice in PBS and then lysed in 1× Cell Lysis Buffer supplemented with $1 \mathrm{mM}$ phenylmethylsulfonylfluoride (Cell Signaling Technology, MA). Fifty micrograms of total protein were subjected to SDS-polyacrylamide gel electrophoresis (Invitrogen, CA) for each cell line followed by immunoblotting with mouse monoclonal E-cadherin, $\mathrm{N}$-cadherin and vimentin antibodies (BD Bioscience, NJ) and BAP1 antibody (Santa Cruz Biotechnology, CA) (1:1,000 in 5\% blocking reagent in Tris-buffered saline/Tween-20) overnight at $4^{\circ} \mathrm{C}$. The following day, blots were incubated with goat anti-mouse IgG conjugated with horseradish peroxidase (Santa Cruz Biotechnology; 1:1,000 dilution) for 1 hour at $25^{\circ} \mathrm{C}$. Signals were visualized with enhanced chemiluminescence reagent (Amersham Pharmacia Biotech, NJ) on X-ray film (Eastman Kodak, NY).

\section{Soft agar colony assay}

Twenty thousand cells were suspended in $0.3 \%$ low melting agarose (Lonza, Rockland, ME) in RPMI containing 20\% FBS. This suspension was overlaid onto a solid layer of $0.6 \%$ agarose in a 6 -well plate. The cells were treated with fresh RPMI containing 20\% FBS every other day. After 2-3 weeks, depending upon the growth, the cells were fixed with methanol, stained with $0.02 \%$ crystal violet, and photographed at $\times 10$ magnification.

\section{In vivo xenograft studies}

All animal experiments were performed in accordance with NIH guidelines and approved by the NCI Animal Care and Use Committee. Cultured cells $\left(5 \times 10^{6}-10 \times 10^{6}\right.$ cells) were injected subcutaneously into the dorsal side of three nude or SCID mice. The animals were examined every week for the development of tumors. All animal care was done in accordance with institutional guidelines. The single tumor for each primary cell was excised and fixed in $10 \%$ formalin to process for routine histopathological examination and to perform immunohistochemical staining for the earlier mentioned markers.

\section{Results}

Primary mesothelioma cultures established from malignant effusions of patients with mesothelioma

Table 1 summarizes characteristics, diagnosis and course of treatment of patients with malignant mesothelioma from whom the primary cultures were derived. Four of the five tumors had epithelial histology and one was predominantly epithelial with focal sarcomatous features. All tumors were positive (15-100\% of tumor cells) for mesothelioma-related markers mesothelin and calretinin by IHC. Four of the tumors were also positive for the cytokeratin 5/6.

\section{Morphologic features, electron microscopy and immunohistochemical staining of primary cell cultures are indicative of their being of mesothelial origin}

Primary cultures from all five tumors exhibited morphologic and immunohistochemical features consistent to those of mesothelial cells. All primary cultures except NCI-Meso17 grew as adherent monolayers characterized by polygonal epithelial-type cells that tended to group together as clusters in a colony-like formation. In addition to polygonal epithelial cells, NCI-Meso17 cells also included spindle like cells, which became the predominant cell population as the cells were maintained in culture.

Cell blocks were prepared from early-passage ( $\leq 5$ passages) mesothelioma cells and sections were evaluated by hematoxylin and eosin (H\&E) and IHC (Figure 1 and Table 1). IHC revealed high levels of expression of mesothelin $(2+$ to $3+)$, and WT1 and calretinin (3+) in three samples (NCI-Meso16, NCI-Meso19, NCI-Meso21). NCI-Meso17, which was derived from a patient who had biphasic disease, was negative for most of the above markers, but retained a few WT-1 positive cells. NCIMeso18, which was derived from an epithelioid mesothelioma, retained moderate expression of calretinin and minimal expression of mesothelin and WT1. 
Table 1 Clinical and pathological characteristics of patients from which primary cultures were established

\begin{tabular}{|c|c|c|c|c|c|c|c|c|c|}
\hline \multirow[t]{2}{*}{ Cell lines } & \multirow[t]{2}{*}{ Sex } & \multirow[t]{2}{*}{ Age $(d x)$} & \multirow[t]{2}{*}{ Ethnicity } & \multirow[t]{2}{*}{ Diagnosis } & \multicolumn{2}{|l|}{ Patient tumor } & \multirow[t]{2}{*}{ TNM stage } & \multirow[t]{2}{*}{ Treatment } & \multirow{2}{*}{$\begin{array}{l}\text { Survival } \\
\text { from diagnosis }\end{array}$} \\
\hline & & & & & Histology & Positive markers & & & \\
\hline NCl-Meso16 & M & 72 & Caucasian & Pleural & Epithelioid & $\begin{array}{l}\text { Mesothelin: 2+, 30\%, } \\
\text { Calretinin, WT1, CK5/ } \\
6 \text { (focal) }\end{array}$ & cT4N1M0 (IV) & $\begin{array}{l}\text { Cisplatin + } \\
\text { Pemetrexed } \\
\text { (6 cycles) with } \\
\text { SS1P (first two } \\
\text { cycles) }\end{array}$ & 8 months \\
\hline \multirow[t]{5}{*}{ NCl-Meso 17} & \multirow[t]{5}{*}{$\mathrm{F}$} & \multirow[t]{5}{*}{63} & \multirow[t]{5}{*}{ Caucasian } & \multirow[t]{5}{*}{ Peritoneal } & \multirow{5}{*}{$\begin{array}{l}\text { Predominantly } \\
\text { epitheliod with } \\
\text { focal sarcomatous } \\
\text { features }\end{array}$} & \multirow[t]{5}{*}{$\begin{array}{l}\text { Mesothelin: 2+, 15\%, } \\
\text { WT1, CK5/6, CA125 }\end{array}$} & \multirow[t]{5}{*}{ NA } & $\begin{array}{l}\text { Debulking + IP } \\
\text { Cisplatin + } \\
\text { doxorubicin }\end{array}$ & \multirow[t]{2}{*}{8 years } \\
\hline & & & & & & & & $\begin{array}{l}\text { IP Pemetrexed + IV } \\
\text { Cisplatin }\end{array}$ & \\
\hline & & & & & & & & IP Taxol & \multirow[t]{3}{*}{34 months } \\
\hline & & & & & & & & $\begin{array}{l}\text { Debulking + IP } \\
\text { mitomycin + } \\
\text { doxorubicin }\end{array}$ & \\
\hline & & & & & & & & $\begin{array}{l}\text { phase ॥ } \\
\text { investigationsl } \\
\text { agent }\end{array}$ & \\
\hline \multirow[t]{6}{*}{ NCl-Meso18 } & \multirow[t]{6}{*}{ M } & \multirow[t]{6}{*}{60} & \multirow[t]{6}{*}{ Caucasian } & \multirow[t]{6}{*}{ Pleural } & \multirow[t]{6}{*}{ Epithelioid } & \multirow[t]{6}{*}{$\begin{array}{l}\text { Mesothelin: 3+, 100\%, } \\
\text { Calretinin, CK5/6, WT1 }\end{array}$} & \multirow[t]{6}{*}{ cT3NOMO (III) } & $\begin{array}{l}\text { Cisplatin + } \\
\text { Pemetrexed }\end{array}$ & \\
\hline & & & & & & & & EPP & \\
\hline & & & & & & & & $\begin{array}{l}\text { Cisplatin }+ \\
\text { Pemetrexed }\end{array}$ & \\
\hline & & & & & & & & Gemcitabine & \\
\hline & & & & & & & & Navelbine & \\
\hline & & & & & & & & $\begin{array}{l}\text { phase II } \\
\text { investigational } \\
\text { agent }\end{array}$ & \\
\hline NCl-Meso19 & M & 19 & African & Pleural & Epithelioid & $\begin{array}{l}\text { Mesothelin: 2+, 100\%, } \\
\text { Calretinin }\end{array}$ & T4N3MX (IV) & $\begin{array}{l}\text { Died before any } \\
\text { specific treatment }\end{array}$ & 3 months \\
\hline NCl-Meso21 & M & 66 & Caucasian & Pleural & Epithelioid & $\begin{array}{l}\text { Mesothelin: 3+, 75\%, } \\
\text { WT1, calretinin, CK5/6 }\end{array}$ & T4 (IV) & $\begin{array}{l}\text { Cisplatin + } \\
\text { Pemetrexed } \\
\text { (6 cycles) with } \\
\text { SS1P (first two } \\
\text { cycles) }\end{array}$ & 13 months \\
\hline
\end{tabular}

NA, not applicable; IP, intraperitoneal; IV, intravenous; EPP, extra-pleural pneumonectomy. Patient tumor mesothelin expression is reported based on the intensity of staining (1+ to $3+)$ and percentage of cells stained (1-100\%).

Electron microscopy analysis further supported the mesothelial origin of these cells, as the long irregular and branched microvilli characteristic of mesothelioma cells were present in all the cell cultures (Figure 1). We also noticed the presence of intracytoplasmic intermediate filaments in all the primary cells and glycogen bodies in some of them. Tonofilaments could also be seen in one of the cell cultures (NCI-Meso21). Thus, the electron microscopy data strongly indicated that the primary cell cultures are of mesothelioma origin.

The cell morphology was retained throughout the 30 passages we tested, and we performed STR analysis at different passages in order to eliminate the possibility of cross contamination among cell cultures (Additional file 1). STR analysis showed only modest changes in DNA fingerprinting profiles between primary tumors and the corresponding cell cultures [22]. We also assessed cell surface expression of mesothelin by flow cytometry in early and late passage cells (Additional file 2). Primary cells which expressed mesothelin at early passages (NCI-Meso16, NCI-Meso18, NCI-Meso19, and NCI-Meso21) continued to express mesothelin in late passage cultures. NCIMeso17 which did not express mesothelin in early passages remained mesothelin negative in late passages. Following thawing, cryopreserved cells could be propagated in culture without a noticeable change in growth and morphology. In all subsequent experiments, cells were used between the third to sixth passages in culture.

\section{Cytogenetic analysis reveals abnormal karyotype in all five primary cultures}

Spectral karyotyping of early passage cell cultures uncovered multiple structural and numerical chromosome abnormalities in all five cultures as summarized 


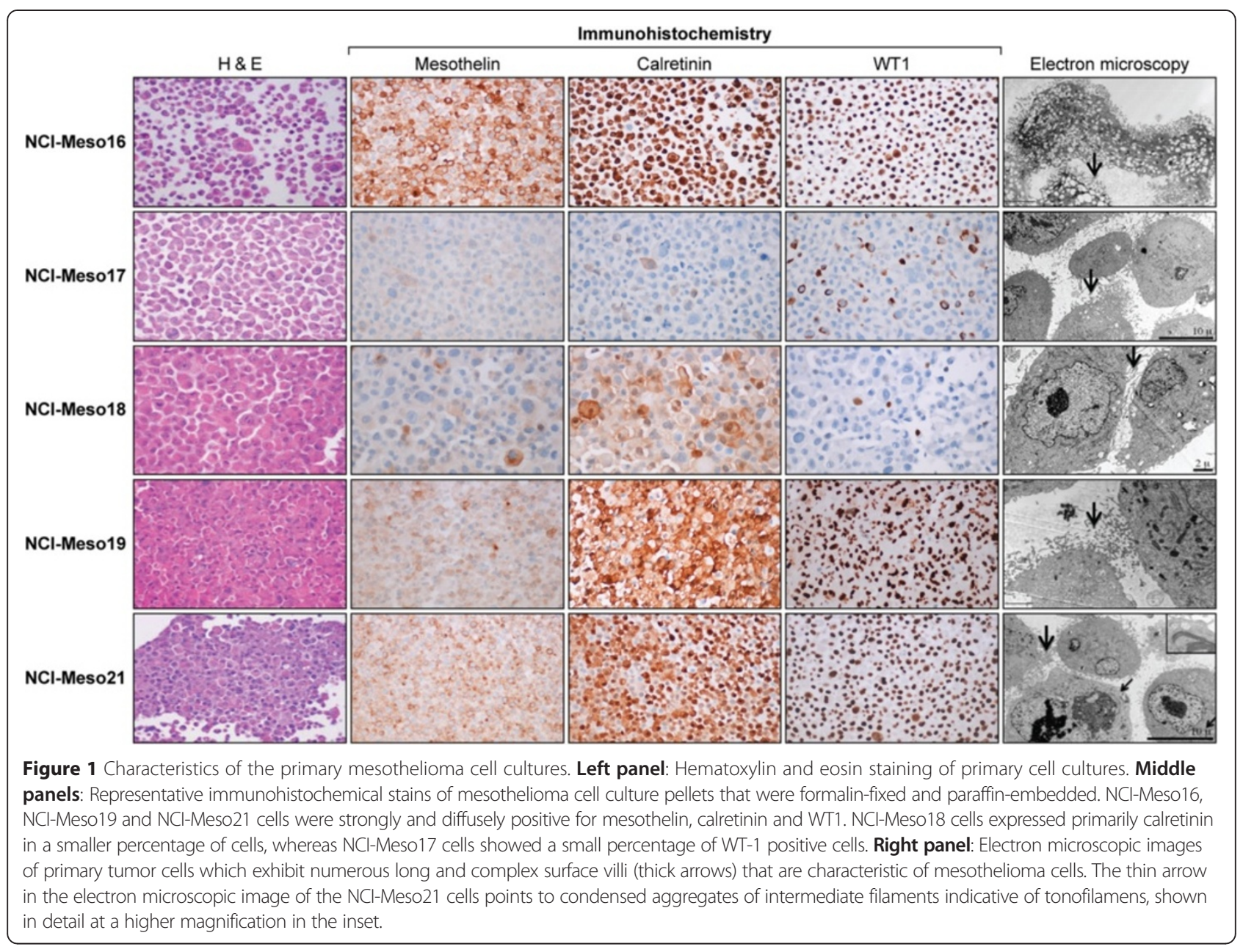

in Additional file 3. The more frequent chromosomal rearrangements included clonal rearrangement or deletions of chromosomes 1 (4/5 cell cultures), 3 (3/5), 9 (4/5) and $22(2 / 5)$. The karyotype analysis showed a very high number of structural abnormalities in NCI-Meso19, a cell culture derived from a mesothelioma of a young patient harboring a somatic TP53 mutation. These results are consistent with earlier reports showing frequent alterations of $1 \mathrm{p}, 3 \mathrm{p}, 9 \mathrm{p}$, and 22 in human mesothelioma specimens and derived cell lines [23]. To assess the stability of karyotypic changes, we evaluated karyotypes of early and late passage cells. This revealed only minor karyotypic changes between passages which are summarized in Additional file 3.

\section{Epithelial-mesothelial markers are present in all five primary cell cultures}

All five cell cultures expressed $\mathrm{N}$-cadherin, consistent with their mesothelial origin as described previously [3]. E-cadherin, an epithelial marker, was also expressed in all cultures except NCI-Meso17, which was derived from the patient who had biphasic disease. NCI-Meso17 had high expression of the mesenchymal marker, vimentin (Additional file 4).

\section{Frequent BAP1 mutations in primary cell cultures}

Mutation analysis of early passage cells revealed BAP1 mutations in 4 of 5 cell cultures (Figure 2A and Table 2). NCI-Meso16 cells had a splice site mutation in intron 4 of BAP1. NCI-Meso17 and NCI-Meso21 had frame shift mutations at the intron15/exon16 junction and in exon 13 of $B A P 1$ gene, respectively (Table 2 and Figure $2 \mathrm{~A}$ ). NCI-Meso18 had a large BAP1 deletion. We found a clear correlation between BAP1 mutation and the absence of BAP1 protein by IHC (Figure 2B). For western blot analysis, we used the mesothelioma cell lines NCIH28 (harboring a BAP1 nonsense mutation) and NCIH2052 (wild type for BAP1) as positive and negative controls, respectively, for the presence of a BAP1 protein (Figure 2C). BAP1 protein expression detected by western blot was preserved after serial passages with late passage cells showing similar expression patterns as early 


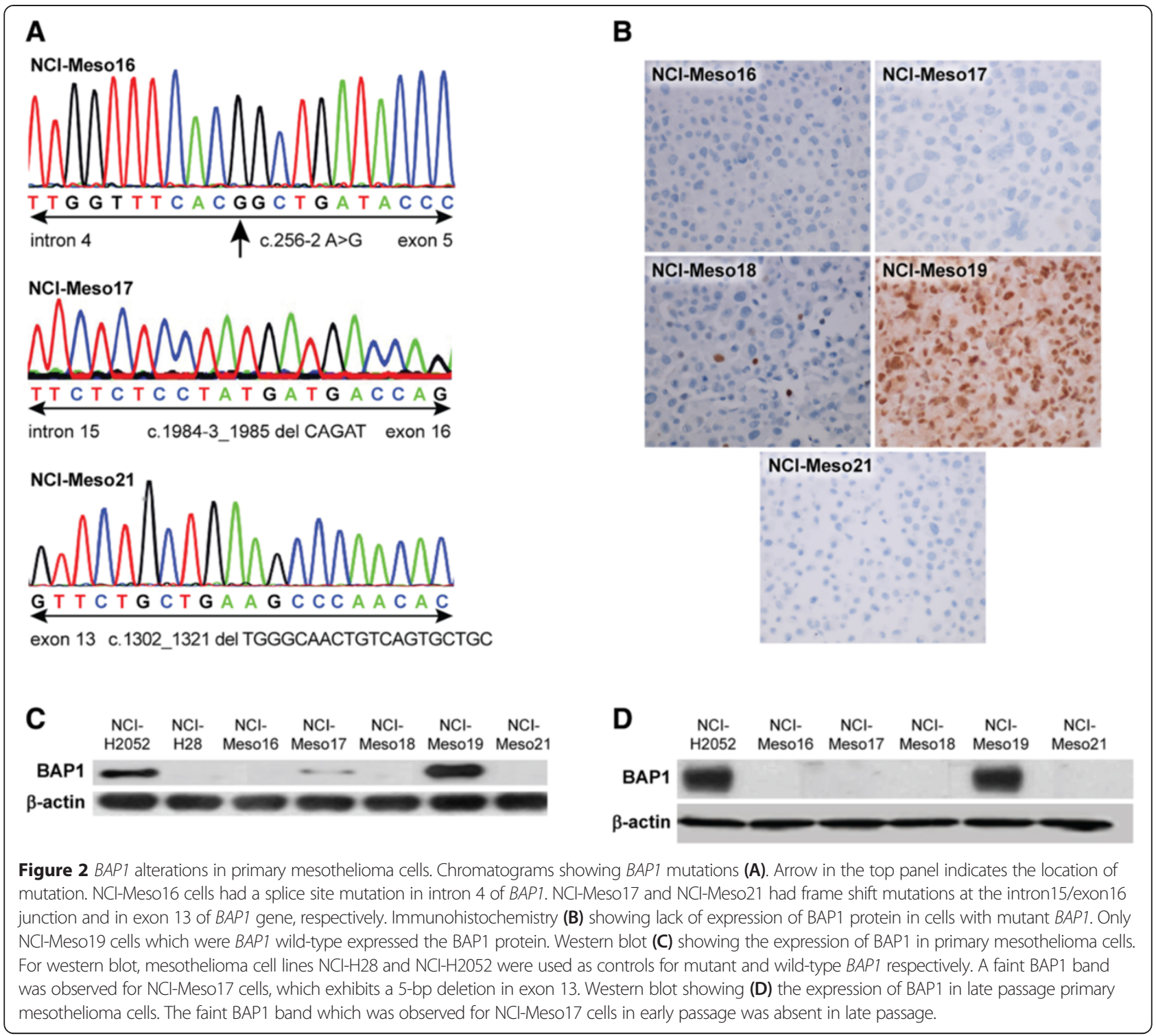

Table 2 Mutations in early passage malignant mesothelioma primary cell cultures

\begin{tabular}{|c|c|c|c|c|c|c|c|c|c|c|c|}
\hline Cell lines & CDKN2A deletion & $B A P 1$ & $N F 2$ & TP53 & $E G F R$ & KRAS & NRAS & $B R A F$ & PIK3 CA & ERBB2 & $A K T 1$ \\
\hline NCl-Meso16 & wt & $\begin{array}{l}\text { Intron } 4 \text { spice site mutation } \\
\text { c. } 256-2 \mathrm{~A}>\mathrm{G}, \mathrm{Hm}\end{array}$ & Wt & Wt & Wt & Wt & Wt & Wt & Wt & Wt & Wt \\
\hline \multirow[t]{2}{*}{ NCl-Meso17 } & $\mathrm{Hm}$ & $\begin{array}{l}\text { Deletion of CAGAT at intron } \\
\text { 15/exon } 16 \text { junction. c. }\end{array}$ & Wt & Wt & Wt & Wt & Wt & Wt & Wt & Wt & Wt \\
\hline & & 1984-3_1985delCAGAT & & & & & & & & & \\
\hline NCl-Meso18 & $\mathrm{Hm}$ & Large deletion & Wt & Wt & Wt & Wt & Wt & Wt & Wt & Wt & Wt \\
\hline NCl-Meso 19 & $\mathrm{Hm}$ & Wt & Large deletion & ${ }^{*} \mathrm{P} 322 \mathrm{~S}$ & Wt & Wt & Wt & Wt & Wt & Wt & Wt \\
\hline \multirow[t]{2}{*}{ NCl-Meso21 } & $\mathrm{Hz}$ & $\begin{array}{l}\text { Homozygous } 20 \text { bp deletion } \\
\text { in exon 13. c. }\end{array}$ & Wt & Wt & Wt & Wt & Wt & Wt & Wt & Wt & Wt \\
\hline & & $\begin{array}{l}\text { 1302_1321delTGGGCAA } \\
\text { CTGTCAGTGCTGC }\end{array}$ & & & & & & & & & \\
\hline
\end{tabular}

All 5 cell lines were analyzed for mutations in BAP1 whole gene, P53 exons 2-9, EGFR Exons 18-24, KRAS and NRAS Codon 12, 13 and 61, BRAF-599-601, PIK3CA Exon 9 and 20, ERBB2 insertion in Exon 20 and AKT1 codon 17. ${ }^{*} T P 53$ heterozygous mis-sense mutation in codon 322 (P322S, Exon 9 ), polymorphism codon 72 (P72R, Exon 4). Hm, homozygous. Hz, heterozygous. Wt, wild-type. 
passage cells (Figure 2D). NCI-Meso17 cells which exhibits a 5-bp deletion in exon 13 demonstrated a faint BAP1 band in early passages which was not detected in late passage cells.

\section{Frequent deletions of CDKN2A in primary cell cultures} We screened cell cultures for deletions of the CDKN2A locus in chromosome 9 p21 by FISH analysis on primary cell cultures. Four of the samples were found to have homozygous deletions of CDKN2A (Table 2), consistent with rates reported in malignant mesothelioma cells [7,24-27]. The percentage of nuclei with a homozygous deletion pattern was more than $60 \%$ in four cultures. One culture had primarily wild type cells, with less than $10 \%$ of cells showing a homozygous deletion of CDKN2A.

\section{Mutations in other genes tested}

We also performed sequence analysis of NF2 and TP53, and hot spot mutation screening for several oncogenes, as summarized in Table 2. A large deletion in NF2 and a missense mutation in exon 8 (P322S) of the TP53 gene were found in one of the primary cultures (Table 2). We did not see mutations in any of the other genes tested.

\section{In vitro soft agar colony growth of mesothelioma cells correlates with tumorigenic potential in vivo}

A soft agar colony assay was performed to examine anchorage independent growth. Three of the five cultures (NCIMeso16, NCI-Meso17 and NCI-Meso21) formed colonies within 3 weeks (Figure 3A). Cells that formed colonies in the in vitro assay also formed visible tumors in mice within 3-8 weeks. Notably, all three of these cell cultures had BAP1 mutations. Tumor growth varied among the cell cultures, with a tumor volume of $100 \mathrm{~mm}^{3}$ achieved between 40 to 80 days after inoculation (Figure 3A).

\section{Early passage mesothelioma cells and their tumor xenografts retain molecular features of human malignant mesothelioma}

The expression of mesothelioma specific immunohistochemical markers in primary cell cultures were preserved in the tumor sections from mouse xenografts (Figure 3B). Furthermore, the xenografts lacked BAP1 expression, as shown by the absence of nuclear staining, similar to the corresponding primary cells. This finding was further supported by detection of the identical $B A P 1$ mutations in tumor xenografts, and the corresponding primary tumor samples and primary cell cultures (Table 3). In addition, xenograft tumors exhibited the same CDKN2A deletion status as in primary cell cultures, except in one case where most but not all cells had a homozygous deletion of $C D K N 2 A$, whereas the reverse was true in the corresponding primary cell culture. This suggests that the tumor cells with loss of CDKN2A had a selective growth advantage in vivo. The two remaining tumor samples completely matched with their primary cultures for their CDKN2A deletion status, further confirming that primary cells obtained from patient's malignant effusions have the same genetic alterations as in the corresponding primary human tumor.

\section{Discussion}

There is a need to develop better preclinical tumor models to evaluate new therapeutic approaches for mesothelioma. Patient derived tumor xenograft models are increasingly being recognized as a robust approach for evaluating the efficacy of novel therapeutic agents, analyzing the process of tumor progression at the cellular and molecular level, and for the identification of new therapeutic targets. However, their utility depends heavily on preservation and stability of biological and morphological characteristics of the primary tumors. Confirmation of this stability is crucial in order to reliably identify molecular responses to treatment in xenografts which can be extrapolated back to patients.

In this report, we describe the establishment of primary mesothelioma cultures and patient derived tumor xenografts with mutational alterations that recapitulate those in the original patient tumors. We isolated malignant mesothelioma cells from the ascites or pleural effusion of five mesothelioma patients and grew them successfully in culture. Furthermore, we performed detailed morphologic and molecular characterization of early passage cultures of these cells and patient derived tumor xenografts in nude mice and assessed their malignant potential in vitro. Using a number of techniques, we demonstrated that these cells were of mesothelial origin and are indeed malignant. Four of the cell lines had BAP1 mutations. We also showed a strong correlation between the mutation and the absence of expression of BAP1 protein. Three out of five cells, all of which were derived from BAP1 mutant primary tumors, exhibited anchorage independent growth and also formed tumors in vivo, suggesting that BAP1 loss may enhance tumor growth in vivo. Both early passage cell cultures and mouse xenograft tumors harbored the BAP1 mutations and $C D K N 2 A$ deletions identical to those observed in the corresponding primary tumor. Given the similarities to the primary tumor, these models offer an opportunity in mesothelioma to study efficacy of novel therapeutic agents and to identify molecular responses to treatment. We believe these models would also enable further studies into functional aspects of $B A P 1$, which is mutated in nearly a quarter of all mesotheliomas.

We also found a strong correlation between the ability of these cells to grow in an anchorage independent fashion in vitro and to induce tumors in vivo, similar to other work [6]. These features, along with the stable nature of these cell cultures, suggest that these early passage cells 


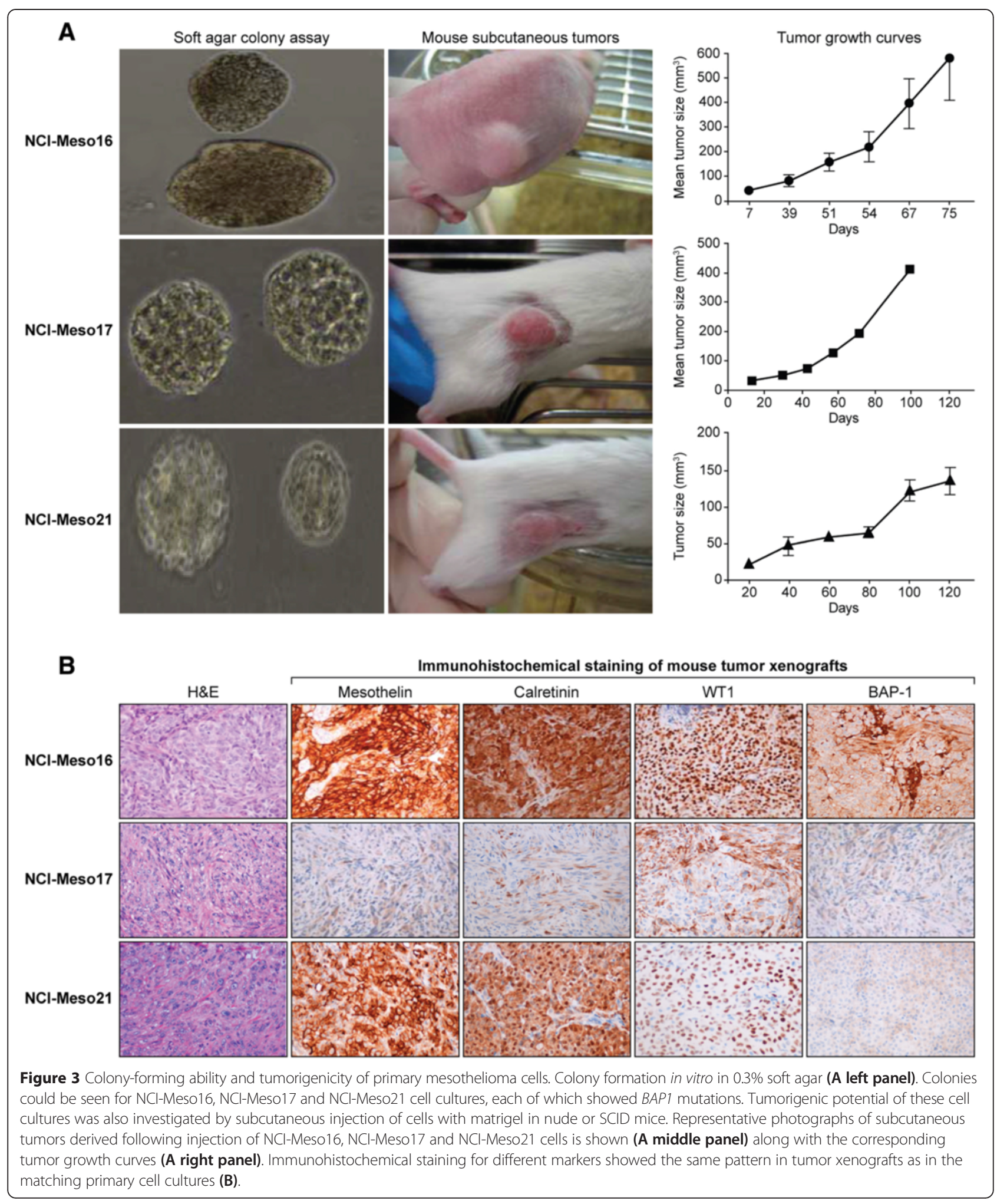


Table 3 Comparison of patient tumors with primary cell culture and with patient derived xenograft in terms of BAP1 mutation and CDKN2A deletion

\begin{tabular}{|c|c|c|c|c|c|c|c|}
\hline \multicolumn{4}{|l|}{ BAP1 mutation } & \multicolumn{4}{|c|}{ CDKN2A deletion by FISH } \\
\hline & $\begin{array}{l}\text { Patient } \\
\text { tumor }\end{array}$ & $\begin{array}{l}\text { Primary } \\
\text { cell } \\
\text { culture }\end{array}$ & $\begin{array}{l}\text { Mouse } \\
\text { xenograft }\end{array}$ & & Patient tumor & $\begin{array}{l}\text { Primary cell } \\
\text { culture }\end{array}$ & Mouse xenograft \\
\hline $\begin{array}{l}\text { NCl-Meso16 (splice site } \\
\text { mutation in Intron 4) }\end{array}$ & Present & Present & Present & NCl-Meso16 (wt) & $\begin{array}{l}\text { Homozygous } \\
\text { deleted cells some } \\
\text { wt cells }\end{array}$ & $\begin{array}{l}\text { Mostly wt. Some } \\
\text { homozygous } \\
\text { deleted cells }\end{array}$ & $\begin{array}{l}\text { Mostly wt. Some } \\
\text { homozygous } \\
\text { deleted cells }\end{array}$ \\
\hline $\begin{array}{l}\text { NCl-Meso17 ( } 5 \text { bp deletion } \\
\text { in intron } 15 \text { - Exon } 16 \\
\text { junction) }\end{array}$ & Present & Present & Present & $\begin{array}{l}\mathrm{NCl}-\text { Meso } 17 \\
\text { (Homozygous } \\
\text { deletion) }\end{array}$ & Present & Present & Present \\
\hline NCI-Meso18 (large deletion) & $\begin{array}{l}\text { Sample } \\
\text { not } \\
\text { available }\end{array}$ & $\begin{array}{l}\text { large } \\
\text { deletion }\end{array}$ & $\begin{array}{l}\text { Does not } \\
\text { form } \\
\text { tumor }\end{array}$ & $\begin{array}{l}\text { NCl-Meso18 } \\
\text { (Homozygous } \\
\text { deletion) }\end{array}$ & $\begin{array}{l}\text { Sample not } \\
\text { available }\end{array}$ & Present & $\begin{array}{l}\text { Does not form } \\
\text { tumor }\end{array}$ \\
\hline NCl-Meso19 (Wt) & Wt & Wt & $\begin{array}{l}\text { Does not } \\
\text { form } \\
\text { tumor }\end{array}$ & $\begin{array}{l}\mathrm{NCl}-\text { Meso19 } \\
\text { (Homozygous } \\
\text { deletion) }\end{array}$ & Present & Present & $\begin{array}{l}\text { Does not form } \\
\text { tumor }\end{array}$ \\
\hline $\begin{array}{l}\mathrm{NCl}-\mathrm{Meso} 21 \text { (20 bp } \\
\text { deletion in Exon 13) }\end{array}$ & $\begin{array}{l}\text { Sample } \\
\text { not } \\
\text { available }\end{array}$ & Present & Present & $\begin{array}{l}\mathrm{NCl}-\mathrm{Meso} 21 \\
\text { (Heterozygous } \\
\text { deletion) }\end{array}$ & $\begin{array}{l}\text { Sample not } \\
\text { available }\end{array}$ & Present & Present \\
\hline
\end{tabular}

Wt- wild-type.

would be useful for functional and preclinical studies. It is noteworthy that the cell cultures that formed colonies in vitro and tumors in nude mice were cell lines that had BAP1 mutations. Previous studies of BAP1 have shown that BAP1 loss promotes colony-forming ability of mesothelioma cells, and that re-expression of BAP1 in BAP1deficient markedly decreases colony-formation [11]. Combined with the fact that these same cell cultures were also tumorigenic suggests that BAP1 loss may also enhance tumor growth in vivo.

Some BAP1 missense mutations have been shown to affect the ubiquitin hydrolase activity of its protein product; however, splice site mutations cause exon-skipping leading to aberrant, out-of-frame transcripts [11]. A recent study has suggested that BAP1 inactivation is more closely associated with the epithelioid subtype of malignant pleural mesothelioma [28]. Consistent with this possibility, 3 of the 4 cell cultures harboring BAP1 mutations in our study had epithelioid histology. Since the $\mathrm{p} 16^{\mathrm{INK} 4 \mathrm{a}} / \mathrm{p} 14^{\mathrm{ARF}}$ proteins encoded by the CDKN2A locus are essential for normal cell cycle control, FISH analysis of this locus can be useful for the diagnosis of early-stage mesotheliomas of epithelial type [29]. Our finding of homozygous CDKN2A deletions in four of five cultures helps confirm the malignant nature of these cells. Recent experimental work has documented the importance of this locus to mesothelioma carcinogenesis. These studies have shown that mice deficient for either p16 ${ }^{\text {Ink4a }}$ or $\mathrm{p} 19^{\text {Arf }}$, the murine homolog of human $\mathrm{p} 14^{\mathrm{ARF}}$, have increased susceptibility to asbestos-induced mesothelioma and that inactivation of both $\mathrm{p} 16^{\text {Ink4a }}$ or p19 ${ }^{\text {Arf }}$ cooperate to accelerate asbestos-induced tumorigenesis [30].
Karyotypic analysis revealed recurrent abnormalities in the short arm of chromosome 1, consistent with a deletion hotspot previously implicated in mesothelioma $[31,32]$. Deletions of chromosome arms 3p, 9p and 22q, which include the tumor suppressor genes BAP1, $C D K N 2 A$, and $N F 2$, respectively, have all been linked to mesothelioma. We also identified variable rearrangements of chromosome 10 in all our primary cultures, a finding that to our knowledge has not been reported earlier for malignant mesothelioma. Thus, investigations of the functional significance of these genomic hotspots, along with the mutational studies, may lead to the identification of molecular targets for the treatment of this disease.

\section{Conclusions}

In summary, we describe the establishment of primary mesothelioma cultures and patient derived tumor xenografts with features that mirror the primary tumors. The primary cell cultures derived from ascitic or pleural fluids of patients with mesothelioma are highly tumorigenic and maintain the histologic and molecular features of the original tumors when grown in murine models. To our knowledge this is the first report that compares the characteristics of the patient's tumors with the primary cells and mouse xenograft at the genetic level in malignant mesothelioma. Given that these primary cultures and patient derived tumor xenograft models recapitulate phenotypic and genetic features of the original primary mesotheliomas, they should prove useful for preclinical studies of novel drug regimens and for functional studies of BAP1 biology in mesothelioma. 


\section{Additional files}

\section{Additional file 1: Short tandem repeat analysis of 5 mesothelioma primary cells.}

Additional file 2: Flow cytometry showing cell surface expression of mesothelin in early and late passage cells. Cells were incubated with the anti-mesothelin mAb MN, conjugated with R-PE or isotype control antibody. Results are shown in terms of histogram plots for each cell line where the area under the blue line depicts the binding of MN antibody and the area under the red line shows the binding of isotype control antibody.

Additional file 3: Table S2. Karyotyping of early and late passage primary mesothelioma cell lines.

Additional file 4: Western blot images showing the expression $\mathrm{E}$-cadherin, $\mathrm{N}$-cadherin and vimentin in primary cell cultures.

\section{Abbreviations}

COLD: Co-amplification at lower denaturation temperature;

FISH: Fluorescence in situ hybridization; IHC: Immunohistochemistry; PBS: Phosphate buffered saline; PCR: Polymerase Chain Reaction; STR: Short Tandem Repeats; SNVs: Single-nucleotide variants.

\section{Competing interests}

The authors declare that they have no competing interest.

\section{Authors' contributions}

$\mathrm{RH}$ and JRT conceived and directed the project. NK, JZ, LX, MC, JT, SB, MGT, and YC carried out experimental works. NK, JZ, AT, LX, MC, JT, SB, MGT, YC, MR, MM, IP, JRT, and RH analyzed data. NK, AT, YC, SB, MGT, JRT, and RH wrote the paper. All authors read and approved the final manuscript.

\section{Acknowledgements}

This research was supported by the Intramural Research Program of the NIH, National Cancer Institute, Center for Cancer Research; additional partial support was provided by NCI R01 CA175691 (J.R.T) and the Mesothelioma Applied Research Foundation (M.C.).

The authors have no conflicts of interest.

\section{Author details}

${ }^{1}$ Thoracic and Gl Oncology Branch, Center for Cancer Research, National Cancer Institute, National Institutes of Health, Bethesda, MD 20892, USA. ${ }^{2}$ Laboratory of Pathology, Center for Cancer Research, National Cancer Institute, National Institutes of Health, Bethesda, MD 20892, USA. ${ }^{3}$ Cancer Biology Program, Fox Chase Cancer Center, Philadelphia, PA 19111, USA. ${ }^{4}$ Molecular Cytogenetics Core Facility, National Cancer Institute, Frederick, MD 21702, USA. ${ }^{5}$ Beth Israel Deaconess Medical Center, Harvard Medical School, Boston, MA 02215, USA. 'aboratory of Molecular Biology, Center for Cancer Research, National Cancer Institute, National Institutes of Health, Bethesda, MD 20892, USA.

Received: 13 October 2014 Accepted: 24 April 2015

Published online: 08 May 2015

\section{References}

1. Thomas A, Hassan R. Immunotherapies for non-small-cell lung cancer and mesothelioma. Lancet Oncol. 2012;13(7):e301-10.

2. Orengo AM, Spoletini L, Procopio A, Favoni RE, De Cupis A, Ardizzoni A, et al. Establishment of four new mesothelioma cell lines: characterization by ultrastructural and immunophenotypic analysis. Eur Respir J. 1999;13(3):527-34.

3. Usami N, Fukui T, Kondo M, Taniguchi T, Yokoyama T, Mori S, et al. Establishment and characterization of four malignant pleural mesothelioma cell lines from Japanese patients. Cancer Sci. 2006;97(5):387-94.

4. Kobayashi M, Takeuchi T, Ohtsuki Y. Establishment of three novel human malignant pleural mesothelioma cell lines: morphological and cytogenetical studies and EGFR mutation status. Anticancer Res. 2008:28(1A):197-208.

5. Shimosato Y, Kameya T, Najai K, Hirohashi S, Koide T, Hayashi H, et al. Transplantation of human tumors in nude mice. J Natl Cancer Inst. 1976;56(6):1251-60.
6. Relan V, Morrison L, Parsonson K, Clarke BE, Duhig EE, Windsor MN, et al. Phenotypes and karyotypes of human malignant mesothelioma cell lines. PLoS One. 2013;8(3):e58132.

7. Cheng JQ, Jhanwar SC, Klein WM, Bell DW, Lee WC, Altomare DA, et al. p16 alterations and deletion mapping of 9p21-p22 in malignant mesothelioma. Cancer Res. 1994:54(21):5547-51.

8. Bianchi AB, Mitsunaga SI, Cheng JQ, Klein WM, Jhanwar SC, Seizinger B, et al. High frequency of inactivating mutations in the neurofibromatosis type 2 gene (NF2) in primary malignant mesotheliomas. Proc Natl Acad Sci U S A. 1995:92(24):10854-8.

9. Sekido Y, Pass HI, Bader S, Mew DJ, Christman MF, Gazdar AF, et al. Neurofibromatosis type 2 (NF2) gene is somatically mutated in mesothelioma but not in lung cancer. Cancer Res. 1995;55(6):1227-31.

10. Bott M, Brevet M, Taylor BS, Shimizu S, Ito T, Wang $L$, et al. The nuclear deubiquitinase BAP1 is commonly inactivated by somatic mutations and 3p21.1 losses in malignant pleural mesothelioma. Nat Genet. 2011;43(7):668-72.

11. Testa JR, Cheung M, Pei J, Below JE, Tan Y, Sementino E, et al. Germline BAP1 mutations predispose to malignant mesothelioma. Nat Genet. 2011:43(10):1022-5.

12. Ventii KH, Devi NS, Friedrich KL, Chernova TA, Tighiouart M, Van Meir EG, et al. BRCA1-associated protein-1 is a tumor suppressor that requires deubiquitinating activity and nuclear localization. Cancer Res. 2008;68(17):6953-62.

13. Kalra N, Ashai A, Xi L, Zhang J, Avital I, Raffeld M, et al. Patients with peritoneal mesothelioma lack epidermal growth factor receptor tyrosine kinase mutations that would make them sensitive to tyrosine kinase inhibitors. Oncol Rep. 2012;27(6):1794-800.

14. Mohamedali A, Lea NC, Feakins RM, Raj K, Mufti GJ, Kocher HM. AKT1 (E17K) mutation in pancreatic cancer. Technol Cancer Res Treat. 2008;7(5):407-8.

15. Xi L, Arons E, Navarro W, Calvo KR, Stetler-Stevenson M, Raffeld M, et al. Both variant and IGHV4-34-expressing hairy cell leukemia lack the BRAF V600E mutation. Blood. 2012;119(4):3330-2.

16. Su Z, Dias-Santagata D, Duke M, Hutchinson $K$, Lin $Y L$, Borger DR, et al. A platform for rapid detection of multiple oncogenic mutations with relevance to targeted therapy in non-small-cell lung cancer. J Mol Diagn. 2011;13(1):74-84.

17. Pan Q, Pao W, Ladanyi M. Rapid polymerase chain reaction-based detection of epidermal growth factor receptor gene mutations in lung adenocarcinomas. J Mol Diagn. 2005;7(3):396-403.

18. Chowdhuri SR, Xi L, Pham TH, Hanson J, Rodriguez-Canales J, Berman A, et al. EGFR and KRAS mutation analysis in cytologic samples of lung adenocarcinoma enabled by laser capture microdissection. Mod Pathol. 2012;25(4):548-55.

19. Nosho K, Kawasaki T, Ohnishi M, Suemoto Y, Kirkner GJ, Zepf D, et al. PIK3CA mutation in colorectal cancer: relationship with genetic and epigenetic alterations. Neoplasia. 2008;10(6):534-41.

20. Li J, Wang L, Mamon H, Kulke MH, Berbeco R, Makrigiorgos GM. Replacing PCR with COLD-PCR enriches variant DNA sequences and redefines the sensitivity of genetic testing. Nat Med. 2008;14(5):579-84.

21. Zhang J, Qiu S, Zhang Y, Merino M, Fetsch P, Avital I, et al. Loss of mesothelin expression by mesothelioma cells grown in vitro determines sensitivity to anti-mesothelin immunotoxin SS1P. Anticancer Res. 2012;32(12):5151-8.

22. Parson W, Kirchebner R, Mühlmann R, Renner K, Kofler A, Schmidt S, et al. Cancer cell line identification by short tandem repeat profiling: power and limitations. FASEB J. 2005;19(3):434-6.

23. Flejter WL, Li FP, Antman KH, Testa JR. Recurring loss involving chromosomes 1,3 , and 22 in malignant mesothelioma: possible sites of tumor suppressor genes. Genes Chromosomes Cancer. 1989;1(2):148-54.

24. Xio S, Li D, Vijg J, Sugarbaker DJ, Corson JM, Fletcher JA. Codeletion of p15 and p16 in primary malignant mesothelioma. Oncogene. 1995;11(3):511-5.

25. Kratzke RA, Otterson GA, Lincoln CE, Ewing S, Oie H, Geradts J, et al Immunohistochemical analysis of the p16INK4 cyclin-dependent kinase inhibitor in malignant mesothelioma. J Natl Cancer Inst. 1995;87(24):1870-5.

26. Illei PB, Rusch WW, Zakowski MF, Ladanyi M. Homozygous deletion of CDKN2A and codeletion of the methylthioadenosine phosphorylase gene in the majority of pleural mesotheliomas. Clin Cancer Res. 2003;9(6):2108-13.

27. Pass HI, Stevens EJ, Oie H, Tsokos MG, Abati AD, Fetsch PA, et al. Characteristics of nine newly derived mesothelioma cell lines. Ann Thorac Surg. 1995;59(4):835-44.

28. Yoshikawa Y, Sato A, Tsujimura T, Emi M, Morinaga T, Fukuoka K, et al. Frequent inactivation of the BAP1 gene in epithelioid-type malignant mesothelioma. Cancer Sci. 2012;103(5):868-74. 
29. Chung CT, Santos Gda C, Hwang DM, Ludovski O, Pintilie M, Squire JA, et al. FISH assay development for the detection of p16/CDKN2A deletion in malignant pleural mesothelioma. J Clin Pathol. 2010;63(7):630-4.

30. Altomare DA, Menges CW, Xu J, Pei J, Zhang L, Tadevosyan A, et al. Losses of both products of the Cdkn2a/Arf locus contribute to asbestos-induced mesothelioma development and cooperate to accelerate tumorigenesis. PLoS One. 2011;6(4):e18828.

31. Lee WC, Balsara B, Liu Z, Jhanwar SC, Testa JR. Loss of heterozygosity analysis defines a critical region in chromosome 1p22 commonly deleted in human malignant mesothelioma. Cancer Res. 1996;56(19):4297-301.

32. Tsujimura T, Torii I, Sato A, Song M, Fukuoka K, Hasegawa S, et al. Pathological and molecular biological approaches to early mesothelioma. Int J Clin Oncol. 2012;17(1):40-7.

\section{Submit your next manuscript to BioMed Central} and take full advantage of:

- Convenient online submission

- Thorough peer review

- No space constraints or color figure charges

- Immediate publication on acceptance

- Inclusion in PubMed, CAS, Scopus and Google Scholar

- Research which is freely available for redistribution 